\title{
Jogo de Empresas: um modelo para a gestão da produção
}

Walter Roberto Hernández Vergara

waltervergara@ufgd.edu.br Universidade Federal da Grande Dourados (UFGD), Dourados, Mato Grosso do Sul, Brasil

Juliana Suemi Yamanari jusuemi@hotmail.com

Universidade Federal da Grande

Dourados (UFGD), Dourados, Mato

Grosso do Sul, Brasil
O artigo apresenta o desenvolvimento de um jogo de empresa na área de gestão da produção como uma nova metodologia de ensino-aprendizagem que envolve diversas áreas de conhecimentos e pode ser utilizado para treinamento e capacitação de discentes e funcionários. O jogo de empresa, denominado GESPROD (Gestão e Produção), permite abordar as atividades relacionadas à gestão de operações de forma dinâmica, sequencial e simultânea, além de envolver diferentes áreas de gestão de uma empresa. Para o desenvolvimento do referido jogo, realizou-se uma revisão sobre os principais conceitos na gestão de operações e sobre modelagem matemática. A simulação do modelo foi feita através de planilhas eletrônicas. Finalmente, a aplicação do modelo mostrou que os envolvidos desenvolveram novas habilidades de gestão, aprendendo simultaneamente novos conhecimentos, além de se sentirem mais motivados por visualizarem na prática o que antes apenas tinham observado de forma teórica.

PALAVRAS-CHAVE: Jogos de empresa. Simulação. Administração da produção. 


\section{INTRODUÇÃO}

O atual cenário econômico mundial demanda das empresas um entendimento sistêmico de diversas variáveis presentes na área de gestão empresarial, mais especificamente, na administração da produção. $O$ ensino aos atuais e futuros profissionais envolve um volume elevado de informações, requerendo uma forma didática e clara para minimizar a complexidade da transmissão do conhecimento. Uma alternativa encontrada pelas empresas e instituições de ensino é o emprego dos denominados Jogos de Empresa (JE). De acordo com Hein (2008), cursos de treinamento, graduação e pós-graduação tem consolidado o uso dos JE, pois os mesmos proporcionam uma melhor aprendizagem, alinhando a teoria e a prática.

Segundo Slack, Chambers e Johnston (2015), os JE têm como objetivo mostrar um ambiente empresarial hipotético construído a partir de um estudo e implantação de um empreendimento. Esses ambientes simulam diversas áreas da empresa através de parâmetros pré-definidos e os jogadores tomam decisões estratégicas e táticas que influenciam o desenvolvimento do jogo. Essa dinâmica proporciona aos jogadores uma vivência próxima da realidade, preparando-os de maneira mais eficiente para o trabalho diário de uma empresa.

A gestão de operações aborda seis funções básicas: finanças, técnicas, desenvolvimento, recursos humanos, sistemas de informação e marketing. No ambiente empresarial todas essas áreas se interligam de maneira complexa e dinâmica, dificultando o entendimento sistêmico das operações da empresa (SLACK; CHAMBERS; JOHNSTON, 2015).

Dessa forma, os cursos que utilizam métodos tradicionais de ensino das funções da gestão de operações tendem a ensiná-las de forma separada, dificultando assim a percepção do aluno sobre as relações existentes entre as diversas operações. Para treinar e/ou formar profissionais capacitados a entender todo o conjunto da administração da produção, o uso dos JE se coloca como uma alternativa viável, pois exige dos jogadores decisões que necessitam da análise de todos os recursos e informações de uma empresa. Além disso, o usuário pode vivenciar o impacto de suas decisões no ambiente empresarial, conseguindo visualizar rapidamente os erros e acertos das alternativas escolhidas (BELL e LOON, 2015).

O objetivo da pesquisa é o desenvolvimento de um JE, em planilhas eletrônicas, que simule um ambiente empresarial, abordando conceitos de administração da produção. Assim, a modelagem matemática é utilizada para mostrar a dinâmica de gestão de operações de uma empresa, inserir o modelo em planilhas eletrônicas, construir o design do JE, desenvolver o manual do jogo e avaliar o modelo desenvolvido. Como objetivos secundários, propõe-se promover a integração do conhecimento científico com a prática empresarial e facilitar a identificação de soluções mais adequadas na tomada de decisão.

\section{REVISÃO TEÓRICA}


O ensino através de Jogos de Empresa não é equivalente ao conhecimento teórico e aplicado, sendo necessário, portanto, considerá-lo como complementar/auxiliar ao processo de aprendizagem, aliando-o às metodologias tradicionais de educação (SAUAIA, 2015; ARBEX, 2005). Em consonância, Ferreira (2000) considera o JE como ferramenta de apoio e elenca quatro vantagens: desenvolvimento das capacidades gerenciais dos participantes e a resposta do mercado simulado em relação a estas estratégias geradas; troca de experiência entre os participantes, colocando à discussão e apreciação do grupo conceitos como autoridade, responsabilidade e valores pessoais; aprendizado através dos erros sem o custo, revelando aos participantes as consequências de suas decisões; e obtenção, em um curto espaço de tempo, de experiência equivalente a vários anos de vivência empresarial.

Para Motta e Quintella (2012), os JE podem ser divididos em duas etapas: a simulação e o jogo. A simulação está restrita a operacionalização das variáveis e o ambiente de risco proporcionado pelas decisões dos jogadores que são responsáveis pelo jogo. Gonen; Brill; Frank (2009) comentam que as vantagens da simulação empresarial podem ser vantajosas por proporcionarem: aprendizado em todas as áreas empresariais de forma ativa; um feedback imediato e rápido ganho de experiência. Ademais, os JE possuem uma versatilidade ímpar e suas utilizações podem variar desde conceitos estratégicos nas empresas até uma nova metodologia de custeio em determinado departamento da organização.

Apesar das inúmeras vantagens do JE, existem algumas limitações relacionadas ao desenvolvimento do jogo. Os modelos matemáticos devem buscar aproximações com a realidade, porém não é possível uma aproximação perfeita. Os JE não conseguem representar completamente a dinâmica de uma empresa, sendo assim, muitas variáveis podem ser desconsideradas ou consideradas de forma inadequada no momento do desenvolvimento. A aplicação do jogo também é fator limitante, pois um público-alvo deve ser escolhido e os participantes podem não apresentar o mesmo nível de conhecimento técnico. Um jogo onde os participantes não estejam entendendo as informações devido à complexidade causará a desmotivação dos participantes e, consequentemente, o comportamento não será próximo da realidade (RIBEIRO, 2007).

Finalmente, verificou-se na literatura que um JE é uma ferramenta alternativa/complementar no processo de ensino-aprendizagem e que as vantagens que a simulação empresarial apresenta sobrepõem as limitações e dificuldades encontradas no desenvolvimento e aplicação de um JE.

\section{ADMINISTRAÇÃO DA PRODUCÇ̃̃O}

A administração da produção, segundo Slack; Chambers; Johnston (2015) engloba as atividades, decisões e responsabilidades dos gerentes de produção. De acordo com Peinado e Graeml (2007), o tema administração da produção é complexo, pois trata de uma ampla variedade de assuntos que não podem ser desagregados, julgando ser necessária uma visão geral e compreensiva das operações e suas abrangências. A administração da produção envolve as ligações existentes entre as diversas áreas da produção, tais como: finanças, marketing, planejamento e controle da produção, recursos humanos, pesquisa e desenvolvimento, entre outras. 
A função de produção na pesquisa foi desdobrada e alguns conceitos foram brevemente abordados: projeto de sistemas produtivos, planejamento e controle em sistemas produtivos, gestão da qualidade em sistemas produtivos, conceitos de finanças e conceitos de marketing.

\section{Projeto de sistemas produtivos}

O projeto de um sistema produtivo deve considerar os seguintes aspectos: arranjo físico e capacidade de produção. Em uma unidade de produção o posicionamento dos recursos transformadores (máquinas, equipamentos, pessoal de operação e instalações) é denominado arranjo físico. $O$ arranjo físico influencia os planos de processos e o foco da produção de maneira direta, enquanto a capacidade de produção deve conter fortes aspectos dos planos de processos e das tecnologias de produto e produção. Na prática, esses aspectos não podem ser desagregados, pois eles se influenciam diretamente e/ou indiretamente (SLACK; CHAMBERS; JOHNSTON, 2015).

Para Martins e Laugeni (2015), um projeto de arranjo físico aceitável deve enfatizar as seguintes atividades que agregam valor: minimizar custos de movimentação de materiais; utilizar espaço físico de forma eficiente; otimizar a movimentação da mão de obra; reduzir tempos de ciclo dentro da operação; facilitar o fluxo de pessoas e materiais; facilitar a manutenção dos recursos; cumprir exigências legais de segurança do trabalho; e manter o acesso visual das operações.

Ainda, uma unidade produtiva pode produzir um determinado número de produtos/serviços, sendo que este "número" pode ser entendido como a capacidade de produção. Peinado e Graeml (2007) definem capacidade de produção como sendo a "capacidade máxima de produção a que se pode submeter uma unidade produtiva em um determinado intervalo de tempo fixo".

A capacidade de produção é abordada de maneira mais complexa, porém, este é um nível mais estratégico e essas definições devem ser compreendidas pelos gestores. O planejamento e controle de sistemas produtivos abordam este assunto de maneira mais coesa, pois a capacidade de um sistema produtivo deve ser convertida em números por meio de análise de demanda e pelo Planejamento e Controle da Produção (PCP). Uma abordagem utilizando a Engenharia de Custos também contribui para análise da capacidade de produção, pois sem a análise de custo, volume e lucro não é possível abordar a Capacidade Produtiva de uma organização (HORNGREN; DATAR; FOSTER, 2013).

\section{Planejamento e controle de sistemas produtivos}

Neste tópico as abordagens estão voltadas para a Previsão de Demanda e PCP. Estas duas abordagens são essenciais para planejar e controlar uma organização produtiva, pois são elementos que dão limites de quanto produzir e os recursos necessários para se atingir o volume de produção desejado, além de fornecerem dados para área de finanças e marketing projetarem resultados financeiros e econômicos. 
Nesse sentido, o primeiro passo do planejamento é estimar a demanda futura porque os resultados obtidos da previsão são utilizados para prever a quantidade de recursos utilizados e os resultados financeiros da empresa (FERNANDES e GODINHO FILHO, 2010; GAITHER e FRAZIER, 2002).

Os meios de se realizar uma previsão de demanda são diversos, contudo, são divididos em dois grupos: métodos quantitativos e métodos qualitativos. Ambos os métodos têm o intuito de prever e qualificar as vendas de uma empresa, porém são diferenciados pelo modelo de abordagem. Na prática os responsáveis pela previsão utilizam uma combinação de métodos qualitativos e quantitativos, com objetivo de melhorar a qualidade da previsão, ou seja, diminuir o erro inerente ao processo de previsão (GAITHER e FRAZIER, 2002).

A empresa define sua demanda e posteriormente deve se programar e controlar as operações com objetivo de atender aos pedidos da melhor maneira possível. Em uma organização, o PCP possui a função de coordenar e aplicar os recursos de produção para que satisfaça os planos de produção instituídos pela organização (TUBINO, 2009).

O PCP apresenta níveis hierárquicos comumente divididos em três tipos de planejamento: longo, médio e curto prazo. No longo prazo são tomadas decisões estratégicas, tais como: automação de um processo, aquisição de novas máquinas, aumento da capacidade instalada, novos processos de produção e novos fornecedores. No médio prazo, o responsável pelo PCP deve estar atento às mudanças de longo prazo e coordenar as atividades de produção - neste nível, são tomadas decisões como: hora extras necessárias para atender a demandas; novas contratações de pessoal operacional; controle de estoque; mudanças nos pedidos; gestão dos materiais. Já no curto prazo, os responsáveis pelo PCP devem decidir as requisições de materiais, quantidade de matéria-prima, necessidade de pessoal, prazos de entregas, controle da produção (GAITHER e FRAZIER, 2002).

Por fim, o PCP requer e fornece dados para todas as áreas, reiterando a interligação dos diversos setores de um sistema produtivo. As informações de estoque, demanda, arranjo físico, finanças, marketing, materiais e qualidade devem ser fornecidas a PCP, para que este possa cumprir com os objetivos da organização (SLACK; CHAMBERS; JOHNSTON, 2015).

\section{Gestão da qualidade em sistemas produtivos}

Para Corredor e Goñi (2010), a gestão da qualidade é um conjunto de conceitos e ferramentas que contribuem para produzir o que foi projetado e/ou aumentar a qualidade do que se produz. Nesse sentido, cada organização deve fazer a escolha do modelo de gestão que mais se ajusta às suas necessidades. A empresa deve saber quais são os fatores que agregam valor ao seu produto ou serviço, e quais desses fatores são percebidos ou não pelos clientes.

As ferramentas clássicas e básicas da qualidade fornecem dados suficientes para que se inicie uma análise de qualquer processo produtivo existente. Martins e Laugeni (2015) afirmam que as ferramentas da qualidade devem municiar os indivíduos da organização com ideias simples, fortes, de fácil entendimento e aplicação. As sete ferramentas são: diagramas de processo; análise de Pareto; diagramas de causa e efeito; diagramas de correlação; histogramas; cartas de controle de processos; e folhas de verificação. 
Uma empresa depende de diversos setores para se manter em operação e atingir seu principal objetivo: o lucro. Porém, um setor de relevância ímpar dentro de qualquer organização é o setor financeiro, o qual disponibiliza uma série de dados e informações sobre as finanças empresariais. Existem diferentes maneiras de se organizar, detalhar, analisar e expor os dados financeiros de uma empresa. O Balanço Patrimonial (BP), Demonstrativo de Resultado de Exercício (DRE) e fluxo de caixa são estruturas financeiras amplamente divulgadas e requisitadas pela legislação dentro de uma sociedade e são os dois elementos de maior relevância dentro da contabilidade geral (BREALEY; MYERS; ALLIEN, 2013).

De acordo com Figueiredo (2011), o Balanço Patrimonial é divido basicamente nos ativos (recursos econômicos mantidos pela empresa), passivos (obrigações com terceiros) e patrimônio líquido (investimentos dos interessados e lucros acumulados), sendo que essas informações em conjunto mostram a situação patrimonial da empresa em uma data específica.

Em contrapartida, o DRE mostra o progresso financeiro de uma empresa em determinado período de tempo. A principal função desta demonstração é apontar lucro ou prejuízo no período, podendo expor quão eficiente foi o desempenho operacional da empresa (FIGUEIREDO, 2011).

O fluxo de caixa é uma ferramenta simples que permite ao gestor financeiro projetar entradas e saídas de recursos da empresa ao longo do tempo, permitindo analisar os períodos em que a empresa vai realizar ganhos ou perdas. Dessa forma será possível realizar projeções confiáveis ao longo do tempo e o gestor poderá entender as ligações entre BP, DRE e Fluxo de Caixa (BREALEY; MYERS; ALLIEN, 2013).

Nesse contexto, um sistema produtivo gera bens e/ou serviços que requerem a aplicação de diversos recursos direta e/ou indiretamente que, consequentemente, remetem à custos. Para Ross et al. (2015), o custo é um esforço exercido, por meio de um processo de produção, somado aos valores de matérias-primas, materiais auxiliares e de consumo e mão-de-obra direta e indireta. Dessa forma, os custos podem ser classificados de acordo com Neves e Viceconti (2013) em: custos diretos, custos indiretos, custos fixos, e custos variáveis.

Por fim, os custos são utilizados para conhecer o valor do estoque, apurar o lucro, determinar o preço de venda, utilização de materiais, cálculo de mão de obra, apuração do orçamento, análise de investimentos e políticas de comercialização (ROSS et al., 2015).

\section{Marketing}

O marketing está ligado aos esforços de vendas que serão empregados para que o cliente seja atendido com a qualidade desejada. Este setor é conectado à área estratégica da empresa, pois define ferramentas de propaganda e políticas de preços e vendas, além de realizar pesquisas de mercado e estimar projeções de venda (KOTLER e KELLER, 2012). Para Grisi (2004), o marketing possui cinco funções básicas dentro de um processo produtivo, que são: análise da situação atual e futura do mercado; seleção de mercados alvos; fixação dos objetivos de 
marketing; decisões sobre o composto de marketing; e estabelecimento de elementos de controle. Este segmento ainda pode ser responsável pela atividade de distribuição e pós-venda, controlando prazos de entrega, definindo atendimentos com garantia e suporte técnico quando necessário.

\section{METODOLOGIA}

A pesquisa é considerada aplicada, uma vez que existe um interesse prático na aplicação dos Jogos de Empresas e será gerado um novo produto (o jogo de empresas). Quanto aos seus objetivos, a pesquisa é exploratória, pois faz uso do levantamento de dados e informações por meio de revisão bibliográfica e entrevistas - esse tipo de pesquisa conduz os pesquisadores a terem uma visão ampla do problema a ser tratado. A pesquisa bibliográfica foi realizada a partir de análise de artigos, periódicos, livros e informações disponíveis na internet e dos principais trabalhos já realizados, revestidos de importância, por serem capazes de fornecer dados atuais e relevantes relacionados ao tema (MARCONI e LAKATOS, 2007). O problema da pesquisa é abordado de forma quantitativa, pois deve traduzir as informações coletadas em números, utilizando o método de modelagem e simulação.

\section{APLICAÇÃO E ANÁLISE DE RESULTADOS}

\section{DINÂMICA DO JOGO DE EMPRESA}

O JE desenvolvido foi denominado GESPROD (Gestão e Produção). O GESPROD é um jogo que simula uma indústria e uma região de indústrias que produzem três tipos de produtos (produtos A, B e C), que são bens de consumo aceitos pelo público e de fácil comercialização. O JE desenvolvido utiliza como ambiente virtual o Microsoft Excel 2007 que permite a aplicação de fórmulas, algoritmos e valores que simulam a realidade empresarial desejada. $O$ jogo simula as funções da administração da produção.

O jogo de empresa projetado tem como objetivo buscar o desenvolvimento do raciocínio lógico dos participantes e dos conceitos que definem a gestão da produção, fatores que influenciam no processo de ensino-aprendizagem. A Figura 1 mostra a estrutura da base conceitual que é seguido na tomada de decisão. Trata-se de uma forma de mapear as variáveis de decisão e os possíveis caminhos a serem seguidos. 
Figura 1 - Ambiente conceitual do jogo de empresas

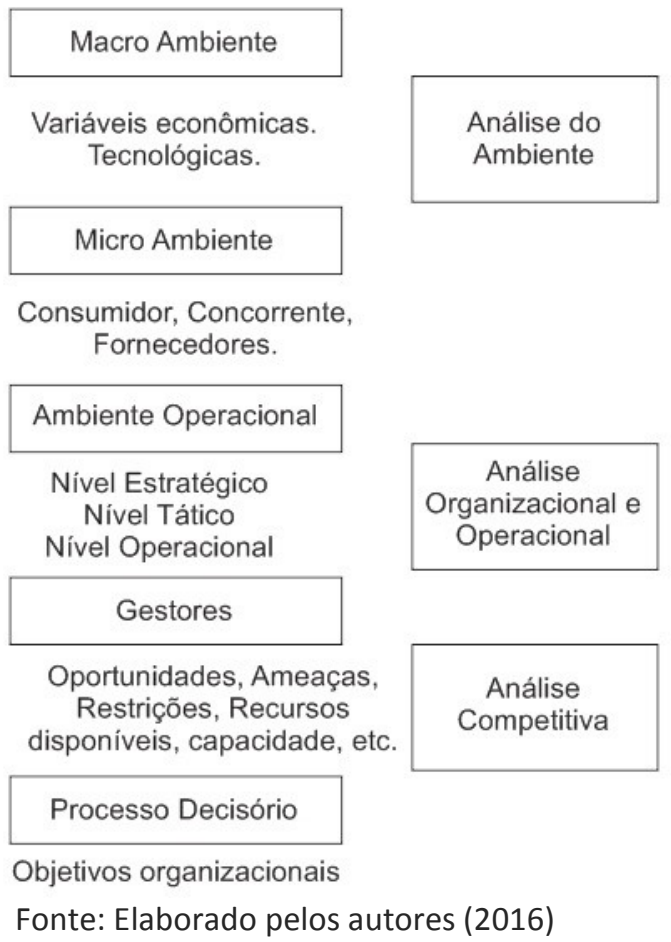

Inicialmente, o animador deve fornecer o manual completo do jogo e fazer uma breve explicação da dinâmica do jogo para as equipes. Posteriormente, deve-se tirar dúvidas dos jogadores sobre o processo de operação das planilhas. $\mathrm{O}$ jogo deverá ser composto por equipes com um número de participantes que pode variar de um (1) a três (3) jogadores. No máximo devem entrar no jogo cinco (5) equipes. A empresa terá uma estrutura organizacional definida, onde os jogadores deverão assumir os cargos pré-determinados e, se necessário, poderão assumir mais de um cargo dentro da empresa.

As principais funções dos jogadores são analisar as informações existentes e tomar decisões necessárias para a operação da empresa. As decisões deverão ser enviadas via e-mail, no formato de um relatório gerado automaticamente pelo conjunto de planilhas dos jogadores. As decisões serão os dados de entrada para o conjunto de planilhas do animador. Estas planilhas deverão simular o período desejado e gerar novos dados e relatórios que deverão ser entregues a cada equipe participante. Além dos relatórios que cada empresa irá receber, ao início de cada rodada um jornal econômico é entregue para as equipes. $O$ jornal econômico irá trazer informações econômicas do mercado, prognósticos, projeções, decisões estratégicas e outros fatos relevantes.

As equipes deverão controlar as empresas durante dois (2) anos, ou seja, oito (8) trimestres, sendo que para cada trimestre deverá existir um conjunto de decisões. Porém, o número de relatórios de decisões é maior que a quantidade de períodos, pois, no primeiro momento do jogo as equipes deverão tomar decisões estratégicas e de longo prazo, gerando um total de nove (9) relatórios de decisões. Neste primeiro momento, não haverá a contabilidade do tempo. 0 tempo real do jogo será de nove (9) semanas, a cada semana acontece um encontro e o mercado é aberto, seja ele de oferta de dinheiro (financiamentos) e/ou matéria-prima. 
No início todas as empresas terão o mesmo capital inicial, que poderá ser designado para a instalação da indústria, contratação de funcionários, compra de máquinas e equipamentos. Com o tempo, cada empresa terá sua própria identidade que será guiada pelos gestores, sendo que o desempenho dessas empresas será continuamente avaliado pelo animador que irá analisar principalmente a lucratividade, rentabilidade e o endividamento.

Os integrantes de cada equipe deverão assumir um ou mais cargos disponíveis na organização: presidente, diretor de produção, diretor de vendas e/ou diretor de finanças. O presidente deve liderar o grupo de diretores e tomar decisões em conjunto com os diretores, além de ser o principal contato com o animador do jogo. Portanto, este deverá ser o responsável pela entrega e recebimento de relatórios durante a execução do jogo.

Os gestores devem decidir pela opção de comprar um terreno e construir as instalações ou alugar um imóvel compatível com as necessidades da empresa. Neste momento, deverá ser decidida a capacidade produtiva da instalação inicial, sendo que todas as empresas terão valores de capacidade pré-determinados para serem escolhidos. Essa capacidade de produção poderá ser aumentada com alguns investimentos e será decidida pelos gestores.

Os funcionários (somente operários) poderão ser contratados e demitidos durante todo o jogo, porém, para demissões existem valores a serem pagos com o objetivo de evitar demissões constantes e demandar mais planejamento dos gestores durante $\mathrm{o}$ jogo. $\mathrm{O}$ jogo necessita de quatro tipos de funcionários: operários, técnicos, administradores e engenheiros. Sendo que o número de técnicos, administradores e engenheiros obedece a uma proporção do número de operários. Quando os gestores contratarem um número " $X$ " de operários, os outros funcionários serão automaticamente contratados. Em caso de demissões, o cálculo das proporções é refeito e outros funcionários podem ou não ser demitidos - se demitidos, as multas também serão contabilizadas normalmente.

Cada tipo de funcionário tem um salário pré-estabelecido e igual para todas as empresas. A equipe terá acesso aos valores do salário e ao percentual médio de encargos sociais praticados no período atual. Os funcionários poderão receber aumento, contudo, este não pode ser retirado. Existe também a possibilidade de horas extras, porém, o custo das horas trabalhadas será mais alto e existe um limite máximo que é estipulado pelo sindicato dos trabalhadores, assim, a divulgação desse índice ocorre via jornal econômico. As empresas que estiverem operando em três turnos não podem realizar horas extras.

As empresas precisam de três tipos de máquinas para produzir, que são: $X, Y$ e $Z$. Cada tipo de produto necessita de uma formação diferente de máquinas, a Tabela 1 relaciona as máquinas e os produtos $\mathrm{A}$, B e C.

Tabela 1 - Relação entre máquinas e produtos

\begin{tabular}{cc}
\hline Produtos & Máquinas \\
\hline \hline A & $\mathrm{X}, \mathrm{Y}, \mathrm{Z}$ \\
\hline $\mathrm{B}$ & $\mathrm{X}, \mathrm{Z}$ \\
\hline $\mathrm{C}$ & $\mathrm{Y}, \mathrm{Z}$ \\
\hline
\end{tabular}

Fonte: Elaborado pelos autores (2016) 
Os investimentos devem ser realizados em três áreas: Pesquisa e Desenvolvimento (P\&D), Manutenção e Qualidade. Sendo que cada área possui uma influência nas variáveis do jogo. A P\&D e Manutenção influenciam nas eficiências das máquinas e processos (capacidade de produção da empresa). A Qualidade será refletida no mercado que a empresa está inserida (reflexo na demanda).

O preço de venda e a propaganda serão as variáveis do setor de marketing, ambos terão influência sobre a demanda da empresa e impactos no mercado da indústria. O preço de venda terá um valor mínimo e máximo regulado pelo mercado e a prática de preços fora destes limites determinará demandas fora do comportamento de mercado, gerando reflexos negativos para empresa. A propaganda determinará o avanço e recuo da empresa dentro do mercado existente. Da mesma maneira que o preço de venda, os investimentos nesta área possuem impactos na demanda, contudo, não existem limites fixados para o investimento. Porém, os reflexos não seguem um formato linear, ou seja, grandes investimentos nem sempre resultarão em grandes demandas. A força de venda também é outra variável deste setor e possui as mesmas relevâncias que a propaganda, contudo, a força de venda possui maior impacto sobre a geração de novas demandas para empresa.

As máquinas disponíveis para produção deverão ser alocadas pelos jogadores de acordo com a estratégia da empresa. Os jogadores deverão de acordo com as capacidades das máquinas e as intenções de produção para cada produto, distribuir a quantidade de máquinas por produto. Os operários de montagem também deverão ser alocados de acordo como os jogadores e divididos entres os produtos. Esta decisão também influencia na capacidade de produção de cada produto. As máquinas e operários formam uma linha de produção para cada produto e suas capacidades gerarão uma quantidade de produtos de acordo com a distribuição dos jogadores e os investimentos realizados.

As empresas devem comprar matéria-prima no formato de leilão para inserir maior dinâmica no mercado. Os jogadores devem solicitar a quantidade desejada e o preço que estão dispostos a pagar. O jogo somente regula um preço mínimo de mercado pela MP e quantidade de disponível em cada rodada. Os jogadores que lançarem os preços menores levam toda a quantidade requisitada, o segundo menor preço lançado pode levar a quantidade requisitada ou apenas um parcial, pois o estoque de MP é fixo e dependerá da primeira requisição dos jogadores de menor preço. Este processo segue para todas as rodadas e todas as empresas, é possível que a empresa fique sem matéria-prima dependendo do preço lançado e do estoque disponível.

As empresas podem pedir empréstimos a instituição financeira do jogo, contudo, o mercado disponibiliza uma quantidade de dinheiro durante cada rodada. As empresas que estiverem com o melhor desenvolvimento financeiro têm prioridade nos empréstimos, no jogo as empresas serão classificadas pelo Lucro Líquido. A classificação será feita de maneira decrescente, ou seja, a empresa de maior lucro terá direito a quantidade de empréstimo que necessitar, já a empresa de menor lucro líquido terá direito ao empréstimo caso ainda exista dinheiro disponível na instituição financeira. 


\section{ANÁLISE DO JOGO DE EMPRESA}

O jogo foi aplicado em uma cooperativa agrícola do estado de Mato Grosso do Sul, localizada no município de Naviraí. A empresa possui duas unidades industriais e seis unidades de armazenamento de grãos. A gestão financeira, administrativa e operacional é acompanhada por uma sede onde ocorre a centralização destas atividades.

Os funcionários escolhidos para participar do jogo possuíam ensino superior e estavam inseridos em rotinas que contemplam a administração da produção, ou seja, são qualificados para entender os conceitos pré-estabelecidos pela simulação desenvolvida. Buscou-se formar grupos de três pessoas, porém, devido a participação limitada de funcionários, todos os grupos formados foram compostos por duas pessoas.

O primeiro contato com o jogo foi uma aula expositiva sobre os conceitos e objetivos do jogo. Posteriormente, o manual do jogo foi apresentado e alguns aspectos explicados. No final do primeiro encontro as decisões da primeira rodada foram geradas pelos grupos, para que os jogadores eliminassem dúvidas sobre a dinâmica do jogo. Os encontros foram programados para cada dois dias.

A divisão das atividades por setores foi aceita e aplicada, contudo, na prática, esta divisão não é percebida, pois, os grupos optaram por tomar todas as decisões de forma conjunta até a formação de um consenso - fator que os jogadores consideraram fundamental, porque era possível tomar a decisão mais adequada para cada empresa.

Como os jogadores não tiveram contatos anteriores com qualquer jogo de negócios, existiu um período maior de adaptação com a dinâmica do jogo. As primeiras rodadas foram mais cautelosas por parte dos grupos e nas jogadas seguintes houve uma busca por melhores resultados e aplicação dos conhecimentos práticos dos jogadores.

Os jogadores enfrentaram nos primeiros momentos dificuldades no momento de definir suas capacidades produtivas e distribuir funcionários e máquinas de acordo com a estratégia de cada empresa. As empresas demoraram em regular os estoques de matéria-prima com a quantidade de máquinas a comprar e sua distribuição de acordo com a linha de produto desejada. A alocação de recursos humanos e os custos incorridos de contratação também não foram bem analisados no início do jogo.

Com as rodadas seguintes, as empresas perceberam suas capacidades e reais necessidades, então começou um processo de alinhamento entre a quantidade a ser produzida, a aquisição de imobilizado e a contratação de mão-de-obra. A compra de matéria-prima foi prejudicada com a falta de cálculos sobre a quantidade requerida, com isso buscou-se disponibilizar matéria-prima em quantidade que não faltasse para nenhuma empresa nas primeiras rodadas. Após esse período de adaptação, o leilão foi implantado e observou-se aumento dos custos por parte dos jogadores para que as empresas não ficassem sem matériaprima.

O algoritmo de demanda utilizado mostrou-se de fácil aplicação e realizou todas as operações de maneira satisfatória. Deste modo, a função multiplicativa de demanda proposta por Lopes, Brondino e Silva (2005) atende de maneira 
adequada a simulação de demanda em um mercado pré-definido. Os participantes também concordaram que havia consonâncias entre os investimentos nas variáveis influenciadores de demanda e o comportamento do mercado, sendo que apenas na primeira decisão houve discussões maiores sobre a demanda que seria gerada, pois não existia um histórico de demanda do mercado.

Percebeu-se que utilizar a dinâmica de iniciar todas as empresas de um ponto "zero" não é muito viável, pois os participantes necessitam mais tempo para adequar as decisões com a demanda, levando as empresas a investirem de forma automática, ou seja, não tomam decisões de maneira racional, apenas determinam valores arbitrários. Para sanar este problema, o animador poderia rodas as empresas de forma única, gerando um histórico de demanda antes do início do jogo.

A Figura 2 representa as ordens de produção da empresa 1 e suas respectivas demandas, sendo que esta empresa 1 representa o comportamento das empresas durante o jogo. A produção e demanda são o somatório dos três produtos durante os 8 períodos do jogo. Eliminou-se o primeiro período, pois, os valores não se distanciam muito da realidade encontrada no jogo. Ainda, percebe-se que a empresa 1 não se antecipou em relação aos picos de demanda, a sazonalidade fator contemplado na função multiplicativa de demanda.

Contudo, nos pontos sem sazonalidade a empresa 1 conseguiu atender a demanda de maneira satisfatória (decisões 1, 4, 7 e 8). Desta forma, a Figura 2 demonstra que o grupo relacionou de maneira correta a capacidade produtiva com a demanda do mercado.

Figura 2 - Produção x Demanda da Empresa 1

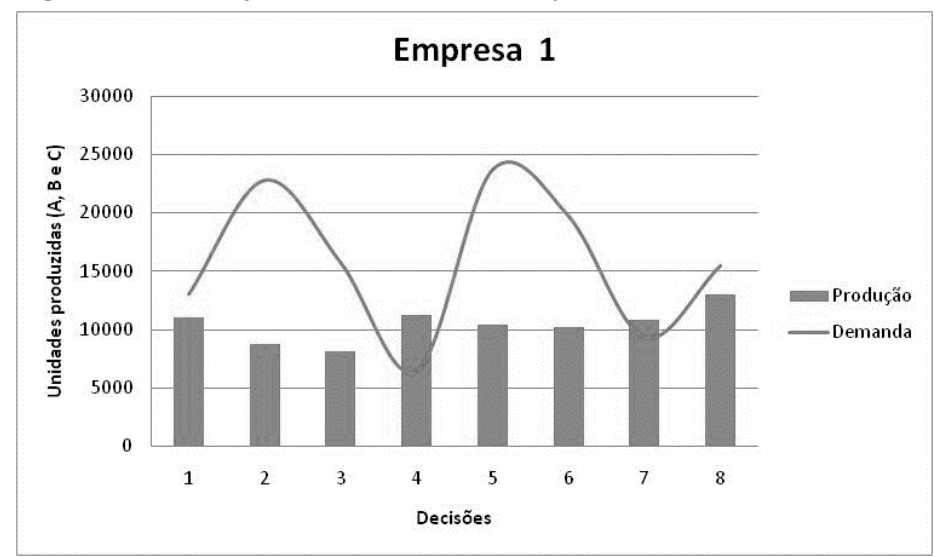

Fonte: Elaborado pelos autores (2016)

Os fatores externos, como a sazonalidade, devem ser previstos pelos jogadores e informados durante o decorrer do jogo pelo moderador. Porém, a estratégia da empresa pode manter um nível de produção constante, com o objetivo de controlar o volume e custos de produção.

As demonstrações financeiras auxiliam de maneira eficiente o desenvolvimento das empresas, e faz com que os jogadores também possuem contato próximo aos demonstrativos contábeis e suas interpretações, o que ajudou a rápida assimilação da estrutura gerencial do jogo. Além disso, os jogadores sempre 
procuravam basear as decisões nas demonstrações contábeis, além de tentar equilibrar as contas, o que muitas vezes não era possível.

De modo geral, as empresas mantiveram saldos positivos e baixos níveis de endividamento e os financiamentos realizados estavam sendo pagos de maneira correta e não prejudicavam o rendimento das empresas, pois, aumentaram a produção para atender a demanda existente no mercado e não para cobrir os custos de produção. Em relação aos custos de produção, houve dificuldade no momento de entender a formação dos mesmos, de tal maneira que houve necessidade de apresentar a planilha de geração dos custos dos produtos vendidos.

A Figura 3 indica o índice de endividamento médio geral das empresas durante as oito rodadas. Este índice indica quanto dos ativos está sendo financiado por capitais de terceiros. De maneira geral, as empresas mantiveram um índice razoável, porém a empresa 3 não aplicou uma boa gestão financeira e fez um financiamento alto durante o jogo.

Figura 3 - Índice de endividamento médio das empresas

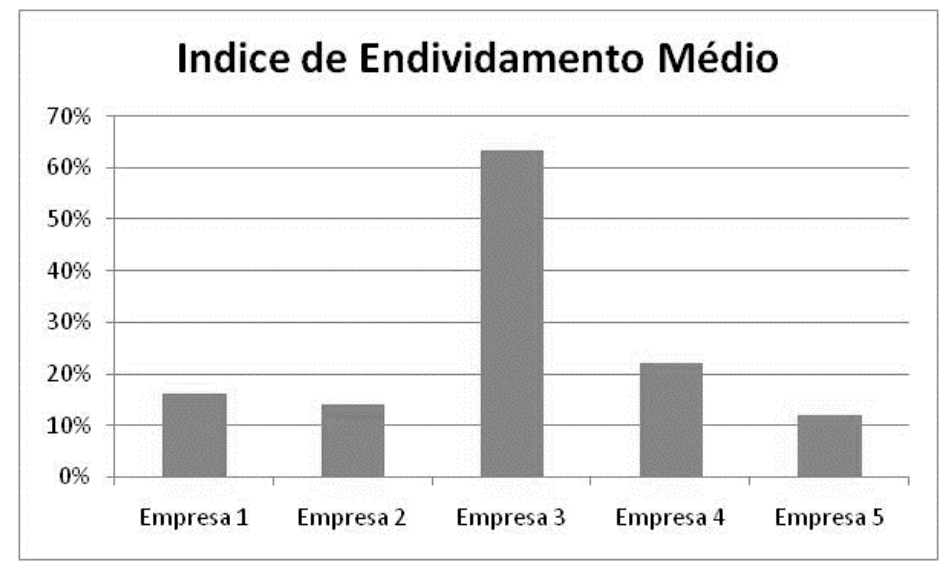

Fonte: Elaborado pelos autores (2016)

As empresas que entenderam a formação dos custos e a demanda puderam diminuir custos de produção e posteriormente diminuir os custos financeiros. Desta maneira, os jogadores geraram lucros para empresas. Vale ressaltar que o lucro é o fator determinante para avaliar as empresas e os jogadores.

O lucro é o objetivo de toda empresa e no jogo simulado também. O lucro indica que os jogadores possuem conhecimento e capacidade de trabalhar com algumas variáveis de uma indústria. Não se pode afirmar que os jogadores agora estão prontos para liderar uma indústria ou assumir cargos de gerência, porém, é correto afirmar que os jogadores estão mais capacitados para entender de forma sistêmica o processo produtivo.

Para gerar lucro, os jogadores tiverem que determinar capacidades de produção, interpretar o mercado externo (demanda e matéria-prima), realizar a gestão dos recursos humanos, interpretar o mercado financeiro, analisar demonstrações contábeis e tomar decisões. Sem o alinhamento destas e outras funções da produção, os jogadores dificilmente formariam lucro dentro do ambiente empresarial. A Figura 4 mostra o histórico do lucro das empresas. 
Figura 4 - Histórico do lucro das empresas

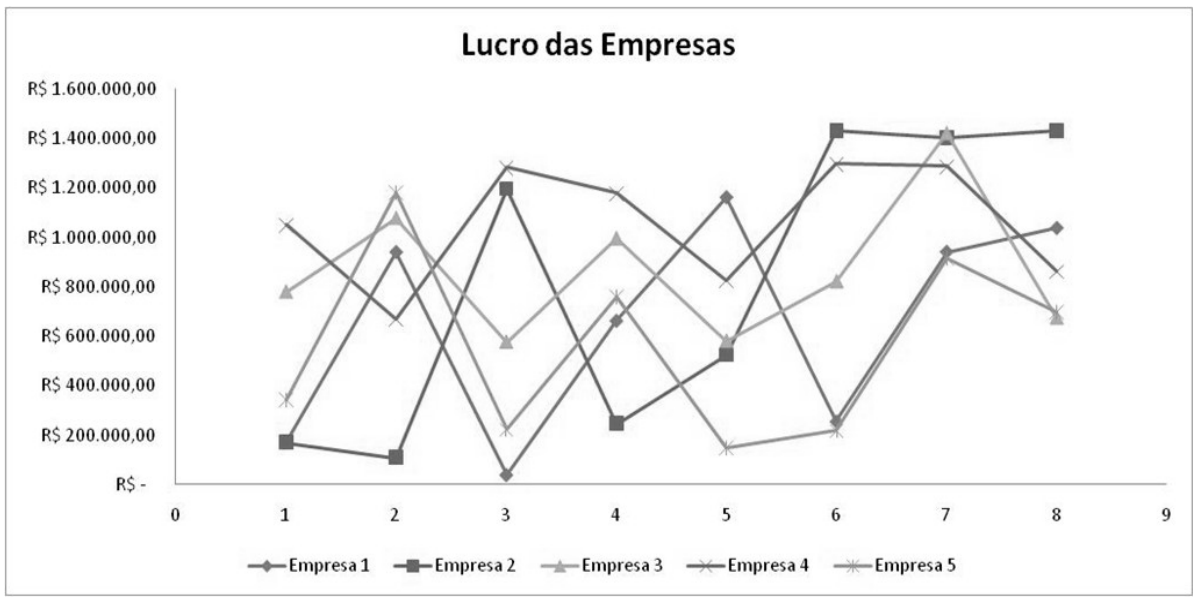

Fonte: Elaborado pelos autores (2016)

Todas as empresas apresentaram lucros positivos durante todo o período do jogo. Porém, é possível observar na Figura 4 que os lucros oscilaram muito durantes os períodos e não estão relacionados com a sazonalidade ou oscilação conjuntura, comportamento que indica a adaptação dos jogadores com a dinâmica do jogo. A empresa 3 mostrou-se bastante estável em relação as outras e apresentou um crescimento ordenado, porém, na última rodada suas estratégias resultaram em uma queda do lucro.

Percebe-se que os lucros foram baixos, algumas empresas chegaram a lucros próximos de zero e as mesmas obtiveram lucros elevados nas rodadas seguintes. Nesse contexto, como a empresa vencedora é determina pelo lucro acumulado, o grupo vencedor ficou evidente apenas nas últimas rodadas. A Figura 5 representa o lucro acumulado das empresas.

Figura 5 - Lucro acumulado das empresas

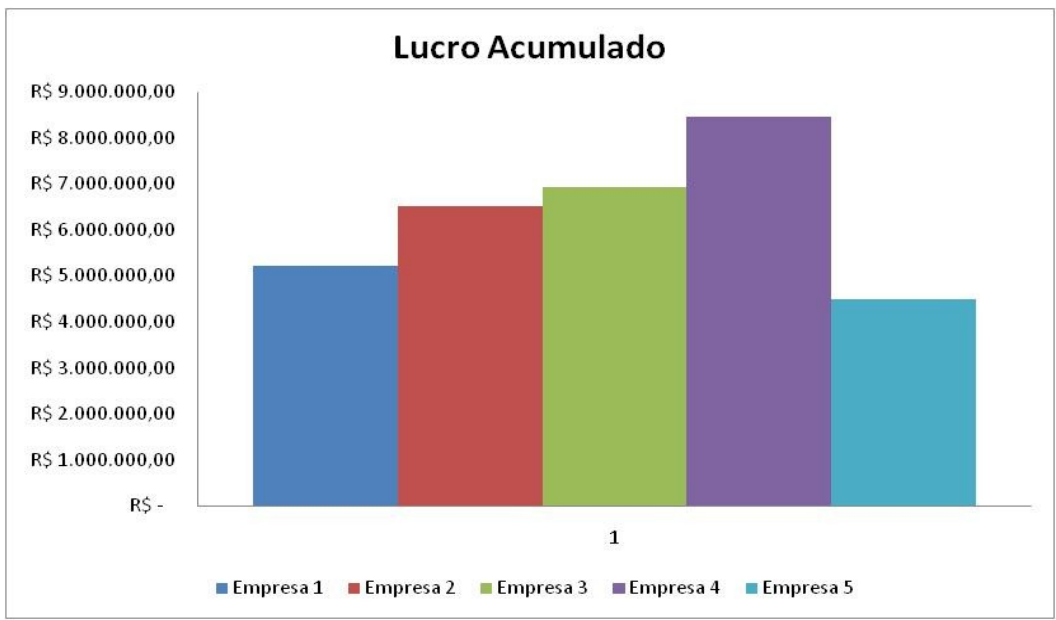

Fonte: Elaborado pelos autores (2016)

A Figura 5 demonstra o vencedor do jogo durante as oitos rodadas. A empresa 4 realizou um lucro acumulado maior que 8 milhões de reais. As empresas 3, 2, 1 e 5 ocuparam os segundo, terceiro, quarto e quinto lugar, respectivamente. Os valores de lucro e custo são elevados em relação ao volume de produto produzidos, como os produtos não são específicos não houve problemas de 
dimensionamento. Porém, simples alterações nos parâmetros da simulação trazem adequação aos valores obtidos de acordo com os produtos desejados para simulação.

\section{CONSIDERAÇÕES FINAIS}

O GESPROD foi desenvolvido como um conjunto de atividades e técnicas em planilhas eletrônicas que simulam de forma satisfatória um ambiente empresarial. Este ambiente está baseado em conceitos e teorias de gestão de operações. Para que a simulação se aproxime deste ambiente, foi utilizado a modelagem matemática.

Um ponto abordado na simulação foi o entendimento dos processos decisórios dos gestores na compreensão de certos fenômenos econômicos que só podem ser explicados através de um comportamento estratégico. Assim, sob o enfoque econômico e visando atingir o princípio da melhor tomada de decisão, ficou implícito que os decisores têm à sua disposição todas as informações necessárias para a resolução de um problema e a escolha da melhor alternativa. Alguns dos participantes relataram que conheciam alguns conceitos mostrados e que ajudou no desenvolvimento de critérios racionais para a seleção de estratégias na gestão da empresa que estavam administrando.

$\mathrm{Na}$ simulação foi possível observar que a melhor alternativa no processo decisório se produz através de um comportamento racional e sistemático dos gestores. Nesse sentido, alguns fatos ajudaram a explicar os comportamentos dos jogadores.

Em primeiro lugar, as empresas simuladas se desenvolveram dentro de um ambiente caracterizado por um conjunto de sucessivas decisões, considerando as "jogadas" de seus concorrentes. Em segundo lugar, os gestores tomaram suas decisões de maneira racional visando obter os melhores resultados econômicos para a empresa. Finalmente, esperou-se que os jogadores concorrentes tivessem também comportamentos caracterizados pela racionalidade, levando em consideração a situação econômica da empresa.

As principais dificuldades do jogo estão relacionadas ao desenvolvimento do modelo. A falta de conhecimento em algumas áreas foi suprida por outros profissionais que trouxeram melhorias significativas na elaboração do modelo e seus componentes, como por exemplo, design, conceitos financeiros e econômicos, marketing e propaganda, engenharia, entre outras.

A estratégia de ensino e aprendizagem utilizada no modelo está baseada no desenvolvimento de uma empresa em um mercado econômico e sob o enfoque de participação de um grupo de discentes do curso de Engenharia de Produção. As equipes atuam dentro de um ambiente de competição econômica com comportamentos racionais e irracionais. O coordenador da simulação apresenta os objetivos do jogo que são compreendidos pelo grupo, valorizando-se as experiências e contribuições dos participantes.

Durante a experiência, foram coletados alguns depoimentos dos discentes, analisando-se os relatórios e os resultados finais apresentados pelas equipes participantes. Constatou-se que o GESPROD proporcionou um ambiente 
estimulante ao ensino e à aprendizagem, por permitir que os discentes fossem agentes ativos no processo.

Também, observou-se o desenvolvimento de habilidades na elaboração, análise e interpretação de relatórios econômico-financeiros, tais como balanços, demonstrações de resultados, fluxo de caixa, entre outros, o que possibilitou aos discentes a oportunidade de desenvolver capacidades no uso de ferramentas estatísticas. Ademais, o jogo permitiu a integração de conhecimentos adquiridos isoladamente nas diversas áreas funcionais de uma empresa, simulando uma situação real. Por fim, como sugestões para futuras pesquisas, o jogo em questão pode ser readequado para uma determinada indústria, colocando-se nomes factíveis aos produtos e alterando os parâmetros de produção. 


\title{
BUSINESS GAME: A MODEL FOR PRODUCTION MANAGEMENT
}

\author{
ABSTRACT
}

The paper presents the development of a business game in production management area as a new teaching and learning methodology that involves many areas of knowledge and can be used for development and training of students and staff. The business game called GESPROD (Management and Production) allows address the activities related to the operations management in a dynamic, sequential and simultaneous way, besides involving different areas of management of a company. For the development of that game, it was held a review of the main concepts in the management of operations and mathematical modeling. The simulation model was made through spreadsheets. Finally, the application of the model showed that those involved have developed new management skills, learning new skills at the same time, and feel more motivated for viewing in practice what previously had only observed theoretically.

KEYWORDS: Business games. Simulation. Production management. 


\section{REFERÊNCIAS}

ARBEX, M. A. O valor pedagógico dos jogos de empresas na aprendizagem de gestão de negócios. Revista FAE, v. 8, n. 2, p. 81-89, 2005.

BELL, R.; LOON, M. The impact of critical thinking disposition on learning using business simulations. The International Journal of Management Education. v. 13, p. 119-127, 2015. crossref

BREALEY, R. A.; MYERS, S. C.; ALLIEN, F. Princípios de finanças corporativas. 10. ed. Porto Alegre: AMGH, 2013.

CORREDOR, P.; GOÑI, S. Quality awards and performance: is there a relationship? The TQM Journal, v. 22, n. 5, p. 529-538, 2010. crossref

FERNANDES, F. C. F.; GODINHO FILHO, M. Planejamento e controle da produção: dos fundamentos ao essencial. São Paulo: Atlas, 2010.

FERREIRA, J. A. Jogos de Empresas: modelo para aplicação prática no ensino de custos e administração do capital de giro em pequenas e médias empresas industriais. 133 f. Dissertação (Mestrado) - Universidade Federal de Santa Catarina, Florianópolis, 2000.

FIGUEIREDO, J. C. N. EXCEL para profissionais de finanças. 2. ed. Rio de Janeiro: Elsevier, 2011.

GAITHER, N.; FRAZIER, G. Administração da produção e operações. 8. ed. São Paulo: Cencage, 2002.

GONEN, A.; BRILL, E.; FRANK, M. Learning through business games: an analysis of successes and failures. On the Horizon. v. 17, n. 4, p. 356-367, 2009. crossref

GRISI, C. C. H. Áreas voltadas para o mercado: marketing industrial. In: CONTADOR, J. C. Gestão de Operações. 2. ed. São Paulo: Edgard Blücher, 2004. Cap. 30, p. 421-438.

HEIN, A. F. Modelagem de um jogo de empresa para o ensino de modelagem de custos. 74 f. Dissertação (Mestrado) - Universidade Federal de Santa Maria, Santa Maria/RS, 2008.

HORNGREN, C. T.; DATAR, S. M.; FOSTER, G. Contabilidade de Custos. 11. ed. São Paulo: Prentice Hall, 2013. 
KOTLER, P.; KELLER, K. L. Administração de marketing. 14. ed. São Paulo: Pearson Education, 2012.

LOPES, S. B.; BRONDINO, N. C. B.; SILVA, A. N. R. Um estudo da dependência espacial em modelos de previsão de demanda por transportes no caso de Porto Alegre. In: Antônio Nélson Rodrigues da Silva; Léa Cristina Lucas de Souza; José Fernando Gomes Mendes. (Org.). Planejamento urbano, regional, integrado e sustentável: Desenvolvimentos recentes no Brasil e em Portugal. p. 173-190. São Carlos, 2005.

MARCONI, M. de. A.; LAKATOS, E. M. Metodologia do trabalho científico: procedimentos básicos, pesquisa bibliográfica, projeto e relatório publicações e trabalhos científicos. São Paulo: Atlas, 2007.

MARTINS, P. G.; LAUGENI, F. P. Administração da produção. 3. ed. São Paulo: Saraiva, 2015.

MOTTA, G. S.; QUINTELLA, R. H. A utilização de jogos e simulações de empresas nos cursos de graduação em administração no estado da Bahia. Revista Eletrônica de Administração, v. 2, n. 72, p. 317-338, 2012. crossref

NEVES, S.; VICECONTI, P. E. V. Contabilidade de Custos. 11. ed. São Paulo: Saraiva, 2013.

PEINADO, J.; GRAEML, A. R. Administração da produção: operações industriais e de serviços. Curitiba: Unicenp, 2007.

RIBEIRO, R. P. Multivest, o jogo de simulação de investimentos em um banco. 147 f. Dissertação (Mestrado) - Universidade Federal de Santa Maria, Santa Maria, 2007.

ROSS, S. A.; WESTERFIELD, R. W.; JAFFE, J.; LAMB, R., Administração financeira. Porto Alegre: AMGH Editora, 2015.

SAUAIA, A. C. A. Laboratório de gestão: simulador organizacional, jogo de empresas e pesquisa aplicada. São Paulo: Editora Manole, 2015.

SLACK, N.; CHAMBERS, S.; JOHNSTON, R. Administração da Produção. 4. ed. São Paulo: Atlas, 2015.

TUBINO, D. F. Planejamento e Controle da Produção. 2. ed. São Paulo: Atlas, 2009. 
Recebido: 27 out. 2016

Aprovado: 11 set. 2017

DOI: 10.3895/gi.v13n2.4896

Como citar:

VERGARA, W. R.; YAMANARI, J. S. Jogo de Empresas: um modelo para a gestão da produção. R. Gest. Industr., Ponta Grossa, v. 13, n. 2, p. 37-56, jun./ago. 2017. Disponível em:

<https://periodicos.utfpr.edu.br/rgi >. Acesso em: XXX.

Correspondência:

Walter Roberto Vergara

R. Carlos Drummond de Andrade, 90, Dourados, Mato Grosso do Sul, Brasil.

Direito autoral: Este artigo está licenciado sob os termos da Licença Creative Commons-Atribuição 4.0 Internacional.

(c) (1) 